\title{
Exploring the overlap: Women Now's feminist humanitarian support and the Community of Practice
}

Judith Bruce

Population Council

Aisha Dennis

Follow this and additional works at: https://knowledgecommons.popcouncil.org/departments_sbsr-pgy

Part of the Family, Life Course, and Society Commons, Feminist, Gender, and Sexuality Studies Commons, International Humanitarian Law Commons, and the Migration Studies Commons How does access to this work benefit you? Let us know!

\section{Recommended Citation}

Bruce, Judith and Aisha Dennis. 2020. "Exploring the overlap: Women Now's feminist humanitarian support and the Community of Practice," Intentional Design: A Community of Practice. New York: Population Council. 


\section{INTENTIONAL

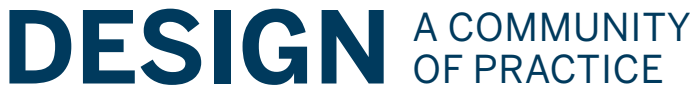

\section{Exploring the Overlap: Women Now's Feminist Humanitarian Support and the Community of Practice}

This conversation took place between Judith Bruce, Senior Associate and Policy Analyst of the Population Council, and Aisha Dennis, former Program Director for Women Now for Development. Women Now for Development's mission is to initiate programs led by Syrian women that protect Syrian women and children across socioeconomic backgrounds and empower women to find their political voice and participate in building a new, peaceful Syria that respects and safeguards equal rights for all its citizens. Aisha's impressive breadth of expertise includes conflict resolution and the

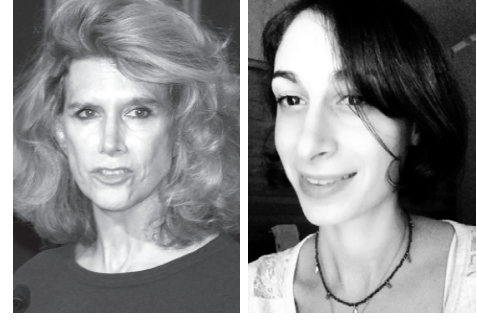

Judith Bruce and Aisha Dennis application of international law through strategic litigation, as well as practical experience in supporting Syrian refugees, especially girls and women, in humanitarian and emergency settings, such as in Lebanon, Syria, and Turkey. In this interview, Judith and Aisha explore the ways in which Women Now's feminist approach to building thoughtful programming for Syrian women and children shares similarities with the Intentional Design approach of the Council's Community of Practice.

Judith Bruce: I was fascinated to read Women Now's position paper entitled "Gender Justice and Feminist Knowledge Production in Syria." I want to bring up a few ideas I found particularly striking that may be a consensual foundation for partnering to support dedicated programs for adolescent girl refugees and other poor intermixed populations, for example, in Jordan, Lebanon, Syria, and Turkey.

Deniz Kandiyoti talks about the "prefabricated nation" (Ali 2018) and the threat that outside, ill-informed analytics ("small project logic") pose to the organic, process-oriented learning that Women Now promotes. Women Now states: "It is important to include grassroots women's and girls' voices and experiences, offering a valuable way to foster effective and relevant ways to address the current context instead of implementing prefabricated projects and programs."

I take from this that you believe-as we do-that while good policy is always welcome, unless you actively "reach the earth," "real" girls won't get "real" things in "real" places without on-the-ground engagement.

You note that "everyone is affected, and everyday practices have implications for everyone by age and gender, boys and girls, and women and men. And it all needs to be looked at again as an attempt to support the refugees where they are but also prepare them for where to turn to."

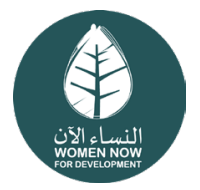




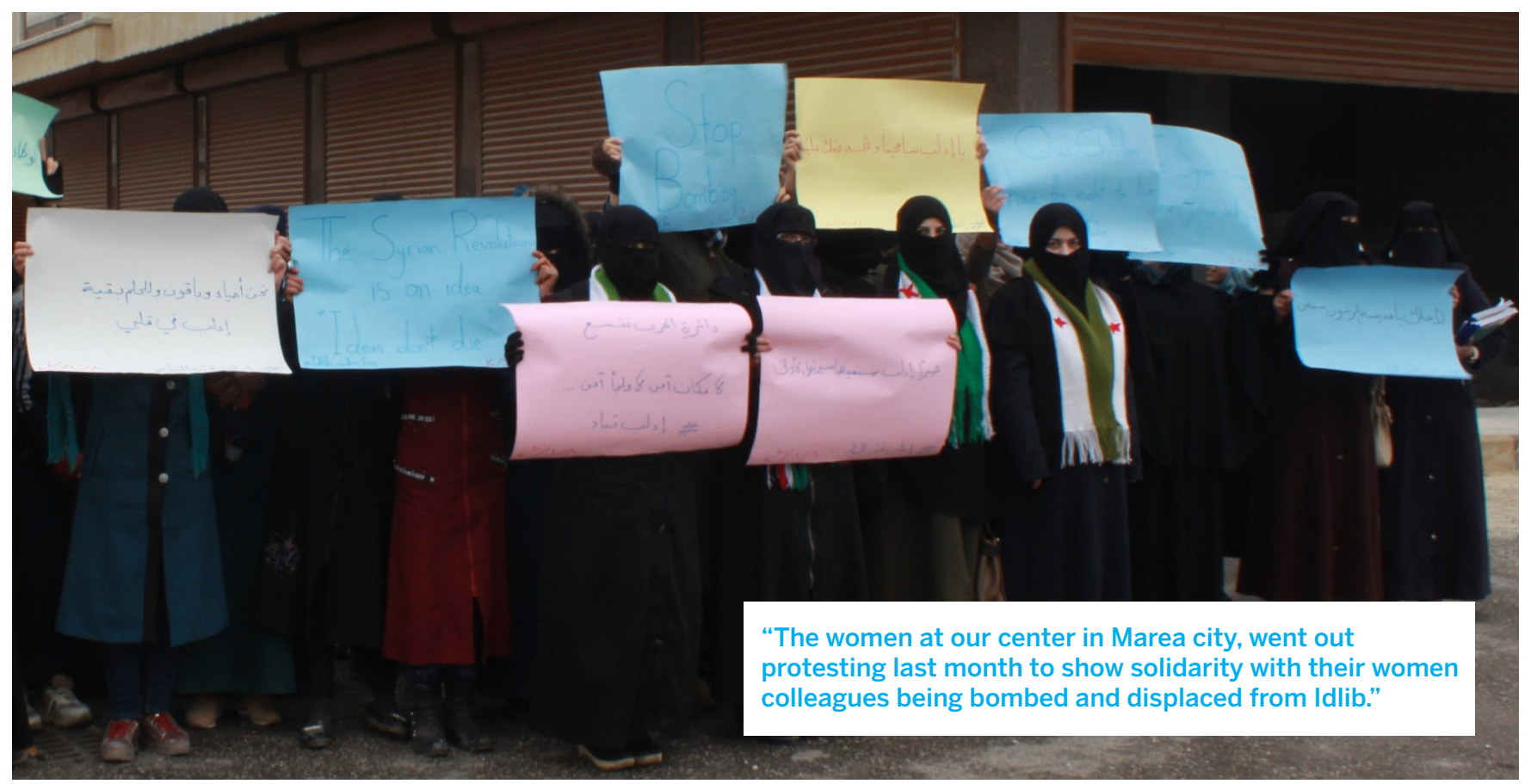

I really love this, because it says activists should consider the everyday and localized material-the social, psychological, and economic dimensions of women's and society's life-as foundational to their mission. Within our Community of Practice, we press for the articulation of the Sustainable Development Goals at the local, subnational level; we believe without this localization, these aspirations have no realistic business plan or geographically anchored accountability.

There's a special "call-out" for women activists and feminists to propose their own understanding of social, economic, and political justice, which often moves one much closer to home. I take from this that you believe, as we do, that governance at the core means communities that work for everyone, an active attempt to assure much more reliability in access to core health, environmental, schooling, financial, and livelihoods opportunities. It's not simply a matter of "rule of law," but it's something that's more operational in girls' and women's lives.

"The personal is political" is often repeated. In our Community of Practice we agree and believe that adolescent girls and their advocates geographically anchored and with program capacity have untapped potential as political actors and movement builders; we hope that our learning and technical exchanges tool the process by which their personal experience becomes politically effective.
You comment that the characterization of your region by external actors undermines fairness and progress. Contextualization is particularly challenging in your region given the degree to which the region between, let's say, Tunisia and Pakistan has been "cartooned," which has undermined policy formation and accelerated stigmatization. We would love to know more about how you generate an understanding of the diversity among countries, within countries, and within districts, and within those districts especially among different age and gender groupings. It seems Women Now is suggesting throughout its statement of values that contextual diversity is a strength and foundational to "identity," not the reverse.

With that as background, l'm interested to hear how Women Now mobilizes these joint principles in engaging adolescent girls through your program.

\section{Some of Women Now's Programming Approaches: Political Engagement and Rights Awareness, Child Marriage, and Establishing a Female Space}

Aisha Dennis: It's great to hear you recognize the quotes from our Gender Justice paper. This piece was the product of research that was conducted over several months based on in-depth consultations with 11 Syrian women inside Syria and living as refugees in Turkey. The purpose was to investigate how women 
conceive of justice and how this can be reflected in current transitional justice mechanisms. In recent months we extended that research, conducting consultations with 50 more women and we will be publishing the results in the coming months.

We believe that the everyday is the way that people experience injustice; the everyday experience is more relevant to people than justice as defined through the courts. We see again and again that women's own survival, as well as the attainment of economic justice, access to livelihoods, and education for their children, is their version of justice, especially vital if their husbands have been detained or killed.

For adolescent girls, we see them as potential political actors starting with analyzing their immediate experiences, their everyday lives, the processes in their homes and schools. At the moment, our work in leadership training and political awareness focuses on women rather than adolescent girls, but we plan to adapt this type of work to the needs of adolescent girls and female youth.

Currently we work with women at multiple levels: social support, education, technical training, building awareness of the dimensions of gender discrimination, and eliciting how they experience their lives in contrast to formal physical and political rights.

Through participating in our rights education or leadership programs, women often report changes in their thinking and behavior, but also changes in those around them. As we build awareness gradually, they start with conversations in the home, they begin to include other family members, including their daughters. Reflecting first on their own rights can change the way that they treat their own adolescent girls, their children. It can change discussions with mothers about rights, can change girls' ambitions, encourage them to continue their schooling, and strengthen their convictions when they have the 'academic' or basic legal knowledge to back up what they're saying. Then they feel more confident in their positions. After these more personal dialogues, we explore broader questions. What is the State? What is the Constitution? What are the processes at the international and local levels which affect them?
JB: Are there any materials or messages that are particularly difficult to deliver because they are presented at a level that seems too remote or because the new idea is actually rejected?

AD: We try to tailor messages to the context. For example, when we worked with women in internally displaced persons (IDP) camps in Idlib, Syria in 2018-19 (in communities where levels of poverty were high and living conditions were extreme) we addressed gender and rights at the local level. We introduced personal status law and basic rights within it. We talked about the local electoral process and how they can get involved. But we weren't going to swamp them with information about international law, the Constitution, and transitional justice mechanisms that bear no relevance to their lives-and in which they currently have no representation. When women have more time with us-when their situation is more secure-we talk in more depth about bodies of law and governance.

On a more everyday level, a key rights issue for adolescent girls is either dropping out of school or lack of access to schooling. So, in Lebanon, social justice requires teaching girls and boys to speak and study in English in order to be able to attend public schools. Syrian children typically haven't learned English before reaching Lebanon and, unfortunately, the Lebanese national curriculum is taught in English.

JB: Where does child marriage fit? There's been a lot written about child marriage (marriage under exact age 18) among the displaced Syrian refugees, and the increased reproductive health risk and higher fertility associated with it, not just in Lebanon but also in Jordan and Turkey. ${ }^{1}$ There appears to be a lower age at marriage among refugees than is typical from their sending communities. Am I correct in reading this as a disruption, not an extension, of a cultural pattern? These issues must be very sensitive, because of the relationship between child marriage, and the perceived reputational and economic protection it offers to families. How does Women Now talk about child marriage with adult women and with girls?

AD: Absolutely, we agree that child marriage has structural drivers. It is not simply "cultural"; it's an economic issue. We address it in several ways and program settings. For example, we have courses in

Mourtada, Rima \& Schlecht, Jennifer \& Dejong, Jocelyn. (2017). A qualitative study exploring child marriage practices among Syrian conflict-affected populations in Lebanon. Conflict and Health. DOI: 10.1186/s13031-017-0131-z. 
health education that include a basic nursing course, women's health, and family health.

Within our health education program in Lebanon last year, we introduced the idea of gender-what gender discrimination is-and we talked about different kinds of gender-based violence and their impact on physical and mental health. We talk about the reproductive and other health impacts of child marriage, so it's slightly indirect. None of the trainers who work on those issues confronted the issue head on with judgment. We don't tell women or girls what they should or shouldn't do; it's more about raising awareness, about the physical, psychological, and health risks.

We also approach child marriage in our psychosocial support sessions delivered by social workers and our Young Mothers Club; they address a whole range of issues, which include child marriage when they're talking to women. When they're talking to adolescent girls as the primary audience, we teach them strategic life planning, encouraging them to write down their dreams, ambitions, and fears. When they do this, it enables them to see where marriage would or would not fit in.

There's a lot of research to show that child marriage is an economic calculation, and this is affirmed by feedback from our centers. We know, for example, that sometimes it's a calculation of "If my child is married then l'Il be able to afford health care, l'll be able to afford a tent, and even food." Another concern is girls' security, given the movement of populations, and the influx of foreign fighters as well as small arms into Syria. Sadly, child marriage is seen as a protective response.

JB: So, you look at their lives as a whole?

AD: Yes, we look at "where they want to get to"-and tell them marriage is not the only option. There are other opportunities. We also work with them to get scholarships to return to schooling of some kind, which directly discourages child marriage.

\section{Expanding the Female Space}

JB: A big innovation in the late 1960s U.S. women's movement was women re-creating female-only spaces. Women felt that they should be free to talk to each other, to be frank about their marriages, their children, aspirations, abuse they may have suffered, fostering their solidarity and trust in privacy, which is vital to remained poor (women who had educational levels equivalent to males made 62 cents on the male dollar), but crucially they were building their social capital, preconditions for more economic equity. They were exercising their right to connect.

In our programmatic experience it is important to acknowledge that the interests of adult women and adolescent girls don't perfectly coincide. In our Community of Practice, a core program strategy is to reduce girls' risks (including sexual and reproductive) and expand opportunities by creating more segmentspecific age and marital status and schooling status groups for girls and young women, independent of parents, including mothers, or partners or male peers. How do you manage the differences between older generations' and younger generations' interests?

$A D$ : We find that adolescent girls particularly want to attend the single-sex groups. They want to convene with their female friends from the community. They make new friends through the programs as well and the female space reassures their parents; it helps us build trust. It's essential to provide a space where they can come together and it's vital to get them there without any reputational or personal security risks. For example, we've learned it is better to provide a bus that goes to the displaced camp area and picks them up individually, than it is to reimburse their transportation. In displaced communities, the parents must be assured of the protection of their girls in reaching the center; absence of such protection is reason enough for parents or husbands to refuse girls' participation. We lay a foundation with the mothers in the community and that helps us to reach out to adolescent girls.

JB: You are also describing a process of not only practical access but intentional signaling of a normative change. From what you describe, the "female space" is established when the bus arrives; it is a tangible example of the girls' rights and of their social participation-to them and to others.

We constantly say, "Nothing's a policy if it's a secret." We've often insisted on having posters that say, "This is a girls' space" and giving the times and dates. That acknowledgement is part of the power. The bus you describe seems to me actively assisted norm setting.

This reminds me of work in Liberia; we created teams of five girls from the same neighborhood who traveled together, walking, in most cases, to a skill-building program. The vision of girl teams walking through 


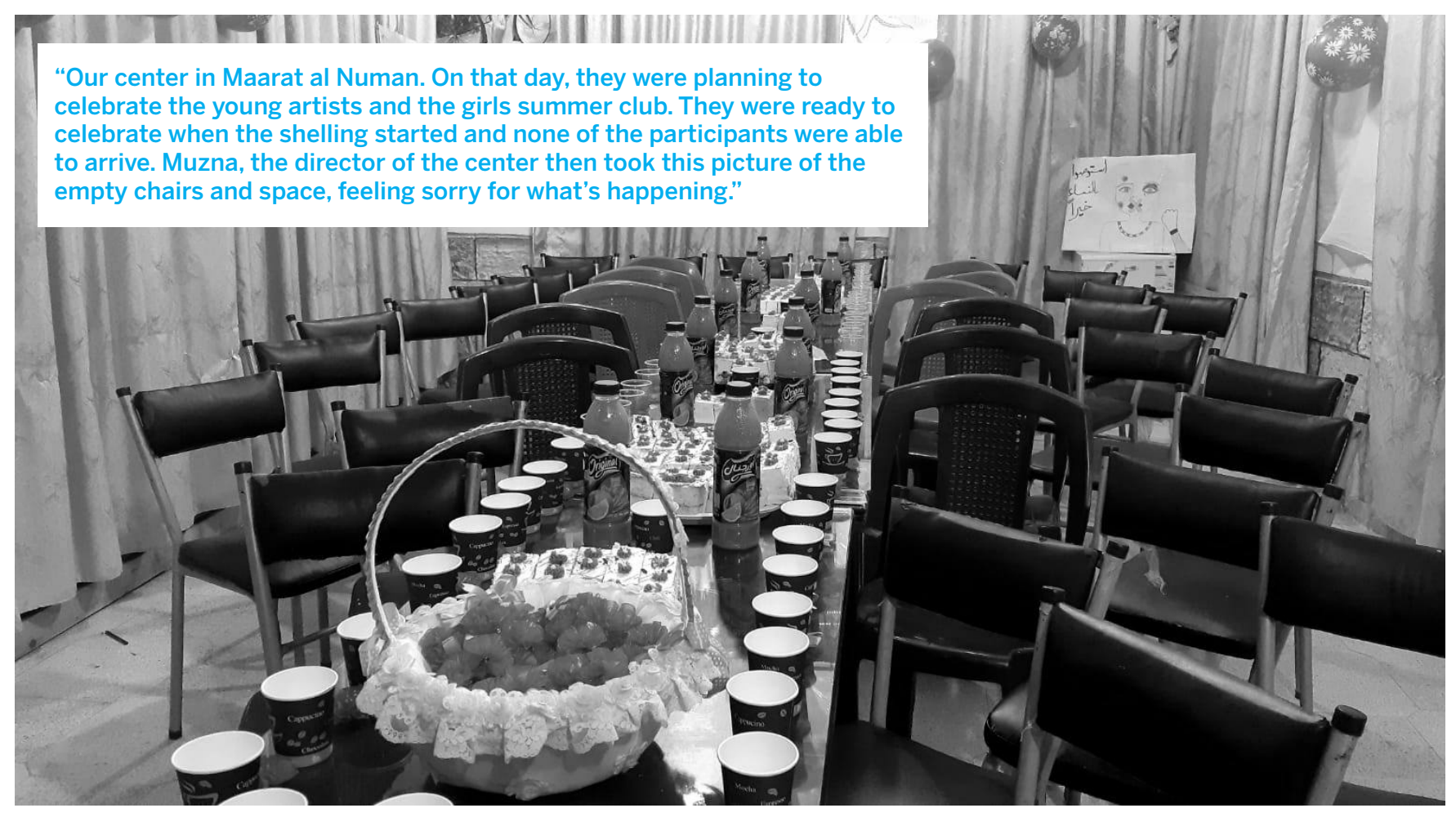

the community was impressive; it not only increased their safety and regular attendance at the program, but was also clear evidence of social transformation. My colleague Sajeda Amin, in studying young female garment workers in Bangladesh, made a similar observation about the visual impact of girls in wage work. She talks about a sea of girls in shalwar kameezes going from home to factories as a daily confirmation of change. $^{2}$

I have another example from Lebanon, relating to understanding location and access in refugee programming in Tripoli. Our partner had engaged a woman's organization that had an office quite distant from the highest concentration of refugees; when they conducted the Girl Roster ${ }^{\text {TM }}$ (a quick household mapping of girls, which revealed the highest concentrations of the refugee girls most in need), the whole program strategy was changed to set up a satellite center near the migration entry point where the numbers of refugee girls was highest.

\section{Investing in Priority Segments of Adolescent Girls and Young Women}

JB: One of the earliest initiatives of our Community of Practice was convening a meeting in 2013 on the needs of adolescent girls in emergencies. The Girls in Emergencies (GiE) Collaborative grew out of this meeting and generated a statement of its conclusions, which included the acknowledgment that within a humanitarian context the youngest adolescents were both absolutely vital and extremely neglected. We saw that the cluster humanitarian organizations were not always working together, that the official UNHCR cluster system put in place in the early days following an emergency facilitated a rapid presence but inadvertently set up a context unresponsive to adolescent girls and other excluded females. The first teams, like the WASH team, would establish toilets, water stands, health posts, and sometimes the rudiments of meeting places in schools. These initial "temporary" structures may stay there as long as 12 to 20 years; coming later, and often with less status and resources, those responsible for dealing with family support, social participations, schooling, and gender-based violence had to "cope" or "override" these earliest decisions to engage adolescent girls and young women.

We affirm that adolescent girls were largely invisible, and even when under tremendous stress were not going to be picked up by and supported by prevailing practices. It was not understood adequately that girls

\footnotetext{
2 Amin, et al. 1998. "Transition to Adulthood for Female Garment-factory Workers in Bangladesh." Studies in Family Planning. URL: https://www.jstor.org/ stable/pdf/172158.pdf
} 


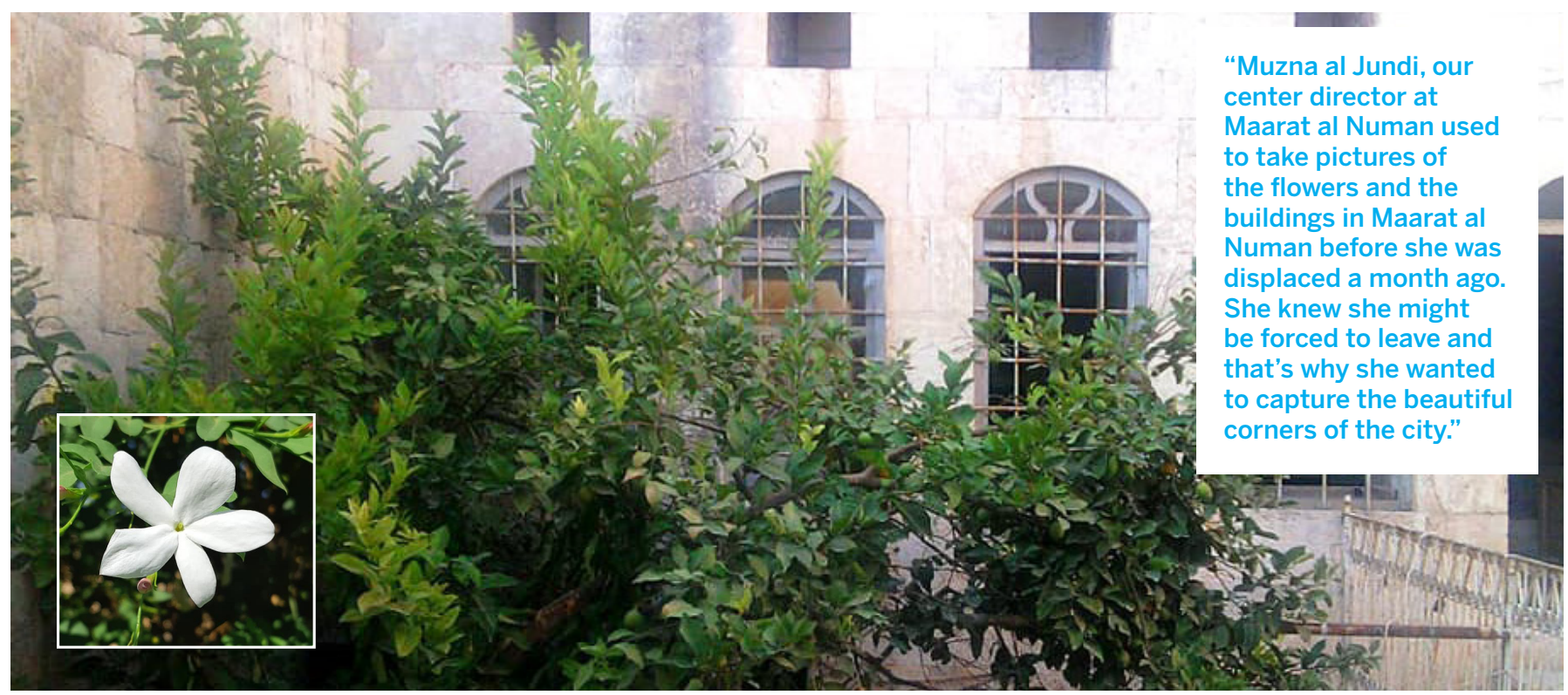

as young as ten are supporting their suddenly single and bereaved mother, effectively in charge of their brothers' and sisters' health. Unless they were visibly pregnant and alone when registering at the border, they were not likely to be called out for attention.

We reviewed case examples which made clear we needed to reach such girls earlier in the emergency not after they'd been excluded from school, carrying the family survival burden, faced assaults and abuse, or married preemptively. So, those were the conclusions from seven years ago, and recently my colleagues in the GiE Collaborative have confirmed that there has been little progress in the context of the Rohingya crisis. So, how do you reach younger adolescent girls earlier in the humanitarian crisis cycle?

AD: I think what the GIE concluded makes a lot of sense. The proportion of adolescent girls we are working with has risen over the last two years, but that's unusual.

Most organizations-even the fantastic ones that are doing great work in these areas-are not reaching adolescent girls in significant numbers. So, we do believe this is a crucial age group full stop. In Idlib, we saw the need for a Girls Summer Club for 10-14-yearolds, including education, psychosocial support, and creative activities, with the opportunity to implement their own initiatives. This was because all of schools were being damaged or destroyed, teachers displaced repeatedly so girls had nowhere to go to get an education. It makes a lot of sense that intervention with this age group has the potential to preempt physical and psychological abuse, economic exploitation, child marriage, and health problems. If girls grow up with a strong social support network, they can better access education, and know and exercise their everyday rights.

JB: Another vital neglected population are girls married as children and bearing children as children. Some have a number of children by the end of adolescence.

We find married girls across many settings are a separate population from married women and unmarried adolescent girls. They are neither comfortable with or "like" either group; they are very socially isolated and unprepared. Their sexual lives and lives as mothers and, often, providers, have commenced abruptly. Perhaps they got medical support for their childbirth, but little beyond it. What could we do better to identify them and reach this group?

AD: For the moment, I don't think that group is being reached in significant numbers. Women Now is unusual because we do work with mothers who are girls, but still the numbers are quite small. The way we are able to reach them is by providing services and safe spaces to discuss subjects of importance. We do provide childcare which, of course, is vital to mothers, particularly the youngest mothers. These spaces and the Women Now approach needs to be protected to assure continued access for adolescent girls who are mothers.

\section{Livelihoods and Savings}

JB: Are you tackling livelihoods directly-for example, what level of nursing skills are taught?

AD: In Syria, graduates of our Nursing courses were able to find paid jobs or volunteer in medical centers 
with NGOs and hospitals; in partnership with UOSSM, we trained 125 women to WHO standards as community health workers and psychosocial support workers. They then delivered gender-sensitive services to around 3,000 people in rural communities. In Idlib, we also trained women in Journalism, Video, and Photo Editing and some women were able to find work in print media and broadcasting, or progress in their careers. We also taught start-up and small business management.

JB: Where do livelihoods, financial literacy, and savings fit in? What special limitations do you have to overcome in the Lebanese setting?

AD: We work with Lebanese women, as well as Syrian and Palestinian; everyone is welcome in our centers. All women in Lebanon are suffering from the economic crisis there, and Syrian women face substantial roadblocks in accessing livelihoods. As you know, women and men who are Syrian refugees are legally restricted to working in three sectors: agriculture, construction, and waste management. Only agriculture is seen as suitable for women.

So, how can we provide skill-building to women, particularly young women and girls who are mothers, that is not seen to be contravening any of that? How do we give them skills that they can take with themknowing they are mobile and their lives unstable? How can they build an income within acceptable cultural and legal boundaries? So, at the moment we are teaching skills in CV writing, in cover letter writing, in interview skills; we teach skills that increase employability in almost any context, like IT and English language skills. All of these skills are useful for both Lebanese and Syrian women. We teach skills like Sewing and Handicrafts, which help us to build trust with the community and establish safe spaces for women and girls, but also enable some women to earn a small income. Honestly, I'm not sure of the solution in Lebanon. This is something we are grappling with at the moment.

JB: In Upper Egypt we explored agricultural processing, which might fly under the "allowed" economic activities in Lebanon. In Upper Egypt, we saw there were large producers of raw agricultural products needing cleaning and sorting and other preparation for marketing. We thought to propose to large suppliers the possibility of bringing unprocessed produce to a central place where married girls or married young women could work together in a female workspace, with childcare and so forth.
Perhaps you could broker such an arrangement allowing young refugee females a collective working space, but with the flexibility and protections they need, and meeting contractual deliverables (such as 100 bushels of cleaned apples) with the larger local farmers.

Work opportunities need to be linked to savings mechanisms, because females need both access to and control of resources. We found throughout our fieldwork-now well documented in extensive microeconomic research-that women's income is family income and of far greater value for health investment than male income (sometimes 10-20 times more powerful). Unless specific measures are taken, women's income is often confiscated. Given the local women's traditions of the gemaya, prevalent among adult women, perhaps a rotating savings system might support younger females and, plausibly, some other safe, informal savings mechanisms.

Another area that may be promising, given the extraordinary lack of access to light and fuel, is green energy production and solar lights and water pumps. Waste management could plausibly be allowed. Our partners in Mozambique are supporting girls in collecting and recycling plastics. Lebanon has a very current and very famous waste management crisis! Your thoughts?

AD: Those scaled agricultural processing, savings mechanisms, and green economic strategies are really great ideas, and maybe we can explore them. I think the point about financial literacy is really important as well; it is something we would really like to work on more.

JB: There are a number of partners we hope will be part of a Beirut-based Learning Circle who have financial literacy materials in Arabic. There is a wealth of field experience especially in Africa, and I think financial literacy will be popular everywhere: affirming the value of girls' economic contribution, establishing that economic identity early, and helping them recognize that their skill and their time counts. It was also a powerful support for later marriage and negotiating reproductive health and sexual risks. They need to understand that they are already crafting livelihoods and contributing; adult women often don't construe their work as "work" because it doesn't yield cash in their hands, and when it does they feel under pressure to give it away and don't make investments in themselves. 
I'm reluctant to make suggestions about banking because the formal banking system in Lebanon is in crisis. Should it recover, we have worked with banks in Kenya to create a savings product for anyone from 10 years old and up. India is now experimenting with giving all 14-year-olds bank accounts in certain states. If I had a country, all children would have accounts from birth. And they would be savings accounts in which it would be easy to deposit and difficult to withdraw, and a portal through which the government makes incentivizing deposits to encourage, for example, school attendance and discourage child marriage. We found that adolescent girls are great savers. They have a higher propensity to save than boys and saving has empowering effects beyond the value of the money saved. Colleagues in South Africa found that girls who had a financial goal changed their sexual safety and reproductive health behavior. It gave them a sense of broadened agency.

\section{The Triple Nexus and the Multilevel Returns on Investing in Very Young Adolescent Girls}

JB: You've written and spoken about the "triple nexus." This refers to three mandates that organizations like yours are ideally meant to pursue simultaneously: peace and justice, development, and humanitarian support. You've observed that pursuing them simultaneously is unduly challenging and that external donors may be impatient with these practical realities.

$A D$ : We are aspiring to pursue the triple nexus: to work across the peace, development, and humanitarian sectors. People have pointed out the differences in language employed in those sectors and also the funding mechanisms. But I don't think people are talking enough about the inherent tension among the "logics" that are employed by each sector and implications for organizations on the ground.

The humanitarian sector, for example, may recognize the importance of community-based work but press local actors to reach the maximum number of the most vulnerable beneficiaries in the shortest possible time for immediate results. In the development sector, the drive is to work with communities on multiple levels for long-term results. And then in the justice and peacebuilding sector, actors will want to work with participants who are already literate and skilled to some extent, and who have access or buy-in to formal justice, security, and governance mechanisms. The focus is on formal mechanisms that are not everyday, as we spoke about before, and are rarely well anchored in the community. There are fundamental differences in these logics.

The dominant sector in our world at the local level is the humanitarian sector. A humanitarian donor organization may come to us and say, "We love your work, we'd love to support you," and we say, "We would love to work with you, because you also do great work." And they continue saying, "We want you to follow a communitybased approach, we like the way that you do things." We say, "OK, great." But then when it comes to, for example, explaining our selection criteria or setting targets or explaining why we work with women in multiple programs, then we face issues translating our approach to fit within the humanitarian logic.

JB: So, the mechanisms and the expectations, the speed and scale, may undermine the learning curve. What about disagreements or incompatibilities in program content?

AD: There is actually less conflict around the program values and content, and more about participant selection criteria, outreach processes, and target setting. Humanitarian donors will recognize in conversation that it is important to allow women and girls to benefit from multiple activities over a sustained period, that this approach results in the deepest impact, and that the choice about which services women access has to come from them, but then place us under pressure to maximize our targets and set "unique" participant number targets. It is not possible to do this accurately without restricting women's choices, so we provide estimates for "unique" target numbers. Or for example, when we are working on a program that relates to peace-building-a leadership program-we need very understanding and flexible partners who validate our attention to the psychosocial needs of the women; we must address women's trauma and daily needs (everyday justice) before or alongside engaging them in more "political" roles.

JB: I'm reflecting on the experiences of Wangari Maathai (of Kenya) and of Rigoberta Menchú (of Guatemala), both Nobel Laureates and both at the policy table but confronting major challenges in how their vision was implemented in their countries. These were mature social advocates. How do we support young female leaders to make change if they're not given programming skills, don't know how to use evidence to plan and evaluate interventions, or know how to manage a staff and budget? This takes us full circle back 
to one of the core principles in Women Now's position paper: how to build from everyday experience and respond to it in programming, including efforts to build political leadership.

AD: Absolutely, we work with women who at the grassroots level don't speak English, but they know local conditions and are potentially powerful. Those invited to higher profile consultations are those with language skills, who can travel. That's a very tiny elite. Unless we build meaningful grassroots leadership, nothing will stick in the long run.

JB: Perhaps the programmatic process of giving voice and skills to the youngest girls-in creating communityanchored female spaces-could be foundational to long-term change, establish nascent governance and service structures, and give adolescent refugee girls practice in building democracy and a safe platform for voice and action? Those girls are going to be in those communities probably for a longer period of time than their mothers, brothers, and fathers. They are in touch with the needs of both younger and older populations. As a cohort, they potentially anchor the formation of a new, just, economically and socially inclusive society and extend the humanitarian investment.

Imagine the potential of giving these girls program identification cards, especially where they're not covered by refugee accords or citizens of the country. It is an "I Am Somebody" card. It acknowledges that there is some relationship between that girl and the community. It signals to them, "Yes, I'm a daughter, yes I'm a sister, and yes I'm a wife" whatever else they are. Skills plus identity assets and a platform from which to act are fundamental aspects of democracy and communities that work for everyone. From this base, as the girls among the garbage collectors did, they can mobilize. They can be part of the vaccination campaign. They can design and carry out the waste management work. They can be part of the reforestation. There are all sorts of needs that require campaigners and implementers. With mentoring, they are natural social innovators. Investing in 10-14-year-old girls may resolve the tension of the Triple Nexus. Remember Greta Thunberg.

AD: I love what you just said! We're thrilled to be working with the Population Council's Community of Practice on this and I look forward to knowing more about the Girls in Emergencies Collaborative.

JB: Thank you!

Judith Bruce is a Senior Associate and Policy Analyst with the Population Council's Poverty, Gender, and Youth program. Through policy analysis, evidence-based intervention design, advocacy, and capacity building, she has changed the way the world thinks about quality of care from the client's perspective and about the power and potential of the poorest, most excluded girls. Bruce leads the Council's efforts to develop programs that protect the health and well-being and expand the opportunities of the poorest adolescent girls in the poorest communities.

Aisha Dennis is former Program Director of Women Now for Development, a feminist, womenled civil society organization. At Women Now, she managed programs that reach thousands of women and adolescent girls annually, in fragile and conflictaffected contexts in Lebanon, Northern Syria, and Turkey. Through these programs, Women Now provides psychosocial support, women's health awareness, adult education, and vocational training as well as promoting women's political participation and rights awareness. She has a background in strategic human rights litigation, specializing in cases addressing human rights abuses during armed conflict. She holds a master's degree in International Law from the School of Oriental and African Studies, the University of London, where her research focused on International Humanitarian Law and the application of Human Rights Law in the context of war and military occupation.

\section{Photo credit: Women Now for Development.}

The Population Council's Community of Practice helps strengthen the capacity of different actors to design, implement, and evaluate effective, scalable programs that build the health, social, economic, and cognitive assets of adolescent girls. 